\title{
Development control system robotic platform for horticulture
}

\author{
Dmitriy Khort, Alexey Kutyrev*, Rostislav Filippov and Stepan Semichev \\ Federal Scientific Agroengineering Center VIM, 1-st Institutsky proezd, 5, Moscow, 109428, Russia.
}

\begin{abstract}
The article presents a control system for a robotic platform for horticulture. The electronic control system consists of a running engine control unit, a stepper motor steering unit, an electronic differential control unit, a power plant automatic on / off control unit, and battery charging balancing. The developed control system of the robotic vehicle contains a central computer that collects information from sensors and sensors, processes it and transmits control signals to the drives of the machine movement. The movement of the robotic platform is carried out both by a radio signal with a remote control, and in offline mode on a pre-set map of the area according to data from the GLONASS/GPS differential receiver of the satellite navigation system. It is also possible to independently control the movement of a robotic platform using a vision system. The autonomy of the robotic platform provides 10 hours of continuous operation in low-light conditions in various weather conditions.
\end{abstract}

\section{Introduction}

With the development of artificial intelligence, scientists, engineers and designers are increasingly turning to the topic of self-driving cars, tractors and robots [1,2]. Currently, the world is actively working on the development of robotic devices for agriculture that can solve a wide range of tasks: spraying, harvesting and caring for plantings [3,4]. Unmanned tractors and agricultural aggregates with intelligent motion control and vision systems that are able to recognize images, distinguish a cultivated plant from weeds, and perform a high-quality technological operation find practical application [5-7]. The use of agricultural robots is aimed at improving the environmental safety of products, minimizing the harmful effects of chemicals on humans and increasing the yield of products [8-10]. At the same time, it is worth noting that most of these machines have not yet been brought to mass production and the final consumer. Therefore, this direction is extremely relevant and in demand for both science and production. In modern conditions of agriculture, the use of robotic machines will allow creating highly intelligent, automated production of agricultural products, which will completely replace manual labor, minimize the negative impact of chemicals on humans and reduce the loss of working time associated with the human factor.

\footnotetext{
* Corresponding author: alexeykutyrev@gmail.com
} 


\section{Materials and Methods}

A prototype of a universal robotic platform structurally consists of a frame with struts, a power plant, an electric transmission, and electronic control system blocks. Two ECMG600$033 \mathrm{U}$ geared motors mounted on the rear wheels drive the universal robotic platform. A LIFAN S-PRO 5500 gas generator and a LiFePo4 24V 105Ah power battery, which allows the platform to operate at full load for at least 10 hours of continuous operation and ensures that the battery is recharged in no more than two hours, power the geared motors. The steering system is a worm-type steering gear with a stepper motor and a stepper motor power controller. A schematic diagram of the control units of the robotic platform is shown in figure 1.

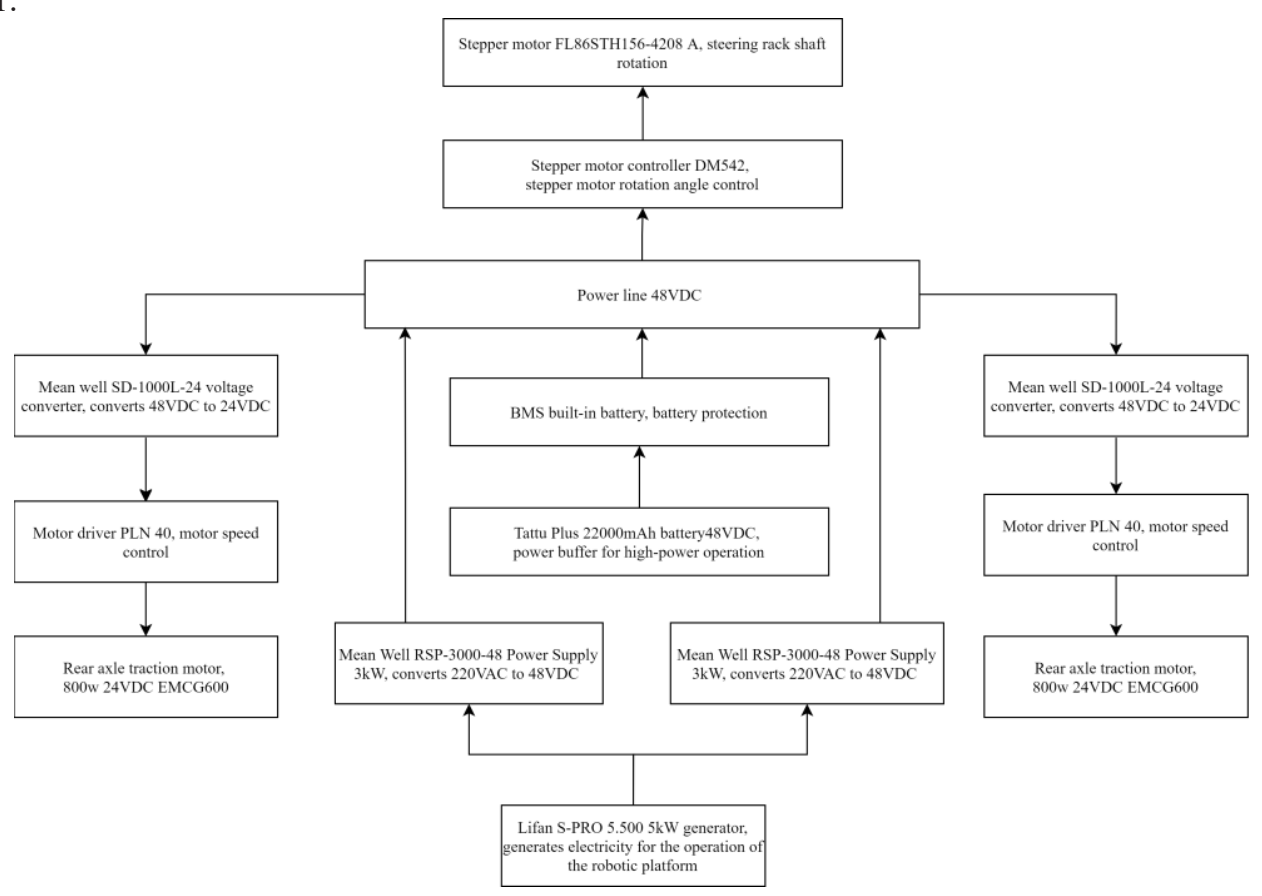

Fig. 1. Schematic diagram of the control of a robotic platform

The electronic control system consists of a control unit for running engines, a steering unit with a stepper motor, an electronic differential control unit, a control unit for automatic switching on and off of the power plant (gas generator) and balancing of battery charging.

The proposed motion control system, power plant and electric transmission, will allow the platform to operate in three modes: remote control, autonomous mode using electronic maps of the area using GPS signals, as well as in unmanned mode using machine vision modules. The control system is located inside the platform body. The technical characteristics of the platform are presented in Table 1.

Table 1. Main tailing dumps of the Sverdlovsk region

\begin{tabular}{|l|c|}
\hline \multicolumn{1}{|c|}{ Basic parameters } & Meaning \\
\hline Curb weight, $\mathrm{kg}$ & 850 \\
\hline Load capacity, kg & 500 \\
\hline Characteristics of the running system: & wheel type \\
Wheel size, mm: - diameter, no more than, mm - width, no & 650 \\
more than, mm & 200 \\
Torque on each of the drive wheels, Nm & 330 \\
Wheel formula & $4 * 2$
\end{tabular}


Table 1. Continued

\begin{tabular}{|c|c|}
\hline $\begin{array}{l}\text { Machine dimensions, not more than, } \mathrm{mm} \text { : } \\
\text { - length } \\
\text { - width, adjustable } \\
\text { - height, no more than }\end{array}$ & $\begin{array}{c}2800,0 \\
1840,0 ; 1960,0 ; 2080,0 \\
1600\end{array}$ \\
\hline $\begin{array}{l}\text { Track width, base, } \mathrm{mm}: \\
\text { - front wheels } \\
\text { - rear wheels } \\
\text { - base }\end{array}$ & $\begin{array}{l}1800 \\
1800 \\
1900\end{array}$ \\
\hline Ground clearance, $\mathrm{mm}$ & 1200 \\
\hline The smallest turning radius, not more than, $\mathrm{mm}$ & 3500 \\
\hline $\begin{array}{l}\text { Forward speed, } \mathrm{km} / \mathrm{h} \\
\text { - working } \\
\text { - transport }\end{array}$ & $\begin{array}{c}2-6 \\
8\end{array}$ \\
\hline $\begin{array}{l}\text { Power plant: } \\
\text { - type } \\
\text { - generator power, } \mathrm{W} \\
\text { - power supply voltage, } \mathrm{V}\end{array}$ & $\begin{array}{c}\text { Gasoline generator } \\
5500 \\
48\end{array}$ \\
\hline $\begin{array}{l}\text { Drive: } \\
\text { - type and quantity } \\
\text { - power, } \mathrm{kW} \\
\text { - motor torque, Nm } \\
\text { - motor shaft speed, rpm }\end{array}$ & $\begin{array}{c}\text { Electric motor with two-stage planetary } \\
\text { gearbox, } 2 \text { pcs. } \\
0.6-0,8 \mathrm{~kW} \\
334 \\
3000 \\
\end{array}$ \\
\hline Remote control operation & $\begin{array}{l}\text { Remote control Fly Sky-T6 FS, transmitter } \\
\text { frequency } 2.4 \mathrm{GHz} \text {, channel width: } \\
500 \mathrm{kHz} \text {, modulation type: GFSK, antenna } \\
\text { length } 26 \mathrm{~mm} \text {, sensitivity } 105 \mathrm{dBm}\end{array}$ \\
\hline Management with technical vision & $\begin{array}{l}\text { The autonomous control system contains } \\
\text { an optical range finder (Lidar), } 4 \text { video } \\
\text { cameras, laser distance sensors, a GPS } \\
\text { navigation station, and an on-board } \\
\text { computer }\end{array}$ \\
\hline $\begin{array}{l}\text { Steering, (type, design) } \\
\text { Stepper motor: }\end{array}$ & $\begin{array}{c}\text { Electric worm-type steering mechanism } \\
\text { ST57-100 } \\
\text { DM556E LEADSHINE Engine } \\
\text { DriverStep-up power converter QS- } \\
\text { 488CCCV-1800W }\end{array}$ \\
\hline Brake system (type, design) & Electric motor braking \\
\hline
\end{tabular}

\section{Results and Discussion}

The electrical connection diagram of the components of the robotic platform (Fig. 2) provides for the launch and power supply of the platform from two sources: the Lifans-pro 5500 generator and the Delta GX12-60 battery pack. 


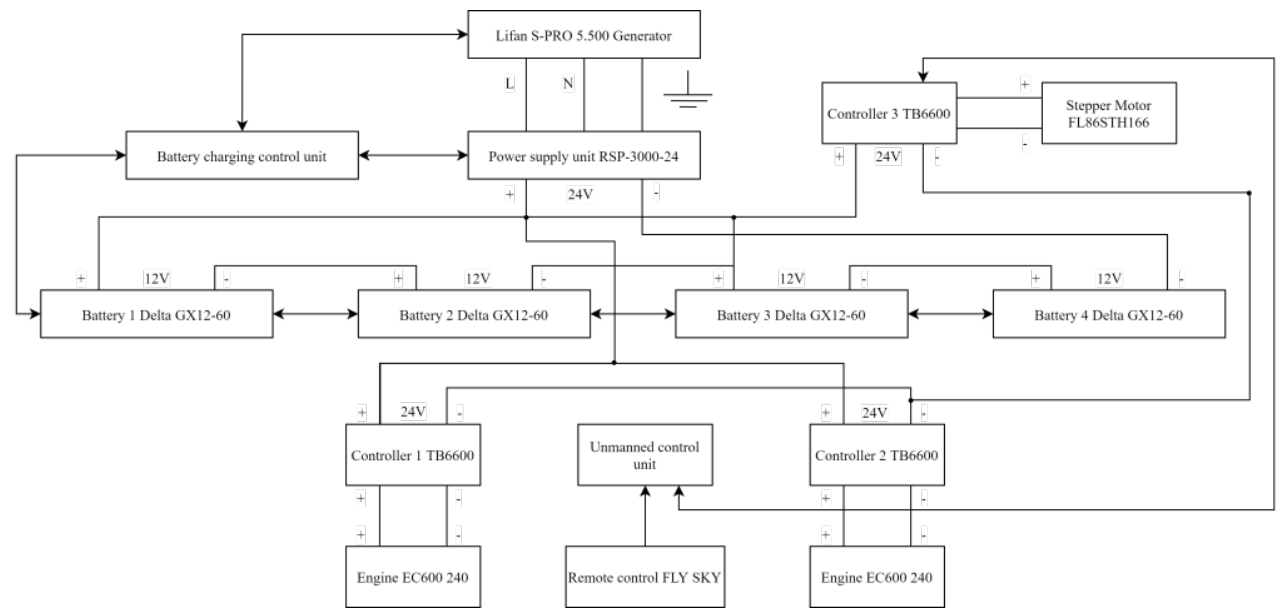

Fig. 2. Schematic electrical diagram of the control of a robotic platform

The main power source is batteries, which, thanks to a certain connection (in series with each other and in pairs in parallel), supply a voltage of $24 \mathrm{~V}$ to the controllers, which are controlled remotely by the control panel. The operator uses the remote control to send signals to the TB6600 and PLN40 controllers, and they in turn control the engines. When the battery is discharged less than $20 \%$, the generator start system is activated, which includes: air speed control, automatic adjustment of engine speed when the load on the battery changes, autorun of the generator using the starter, monitoring the fuel level. If it is necessary to start the generator, the system that monitors the fuel level is activated. When the fuel level is sufficient, the generator turns on the ignition circuit, and the position of the air flap is checked. The air flap must be closed before starting the starter. If the flap is open, the air flap is moved to the closed position by means of a servo drive.

In the PLN 40 motor controller, the speed is regulated using a 5-10 kOhm potentiometer, this method is recommended by the manufacturer of the PLN 40 controllers. This method is adapted to the developed control system of the robotic device (Fig. 3).

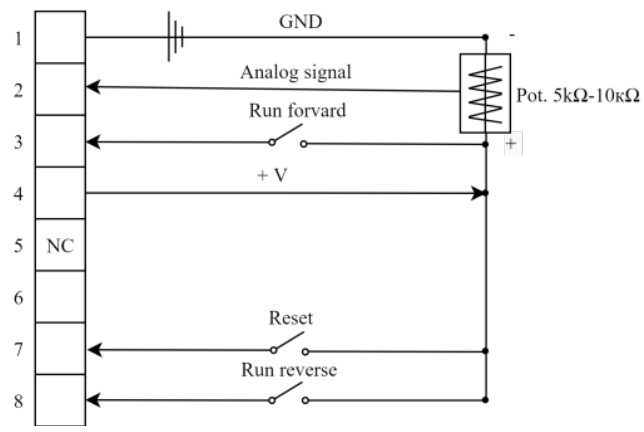

Fig. 3. Control scheme PLN 40

The diagram shows that the speed is controlled by changing the voltage at input 2 . To change the voltage, a device has been developed that converts data from the central control unit to a voltage of $0-10$ to control the speed of the motors using the PLN 40 controller (Fig.4). 


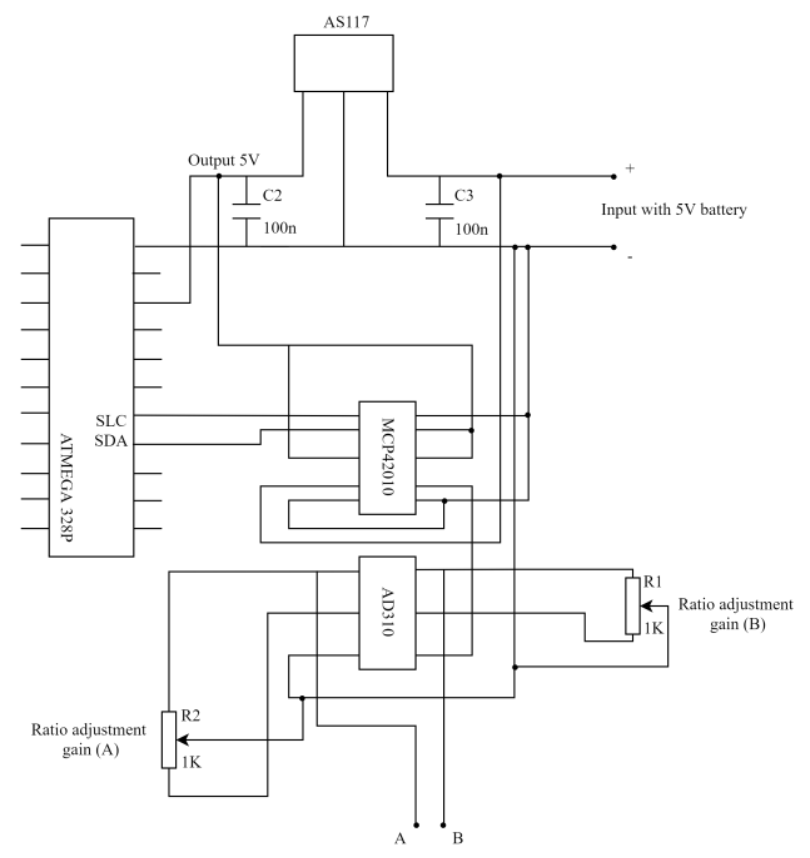

Fig. 4. Motor speed control scheme

To convert the digital signal to analog, the MCP42010-E/SL digital dual-channel potentiometer is used, which can split the voltage $0-5 \mathrm{~V}$ into 128 points. The potentiometer is controlled via a serial peripheral interface (SPI). To form the reference voltage, the AS117 converter is used, which stabilizes the input voltages from 5-20V to a stabilized 5V. The PLN 40 controller reads the voltage from 0 to $10 \mathrm{~V}$. To increase the voltage range, a two-channel AD310 operational amplifier with a gain of 2 is used. To adjust the gain, a subscript resistor is used for each channel. The voltage of $12 \mathrm{~V}$ from the battery is supplied to the voltage stabilizer AS117, a stable voltage of $5 \mathrm{~V}$ is formed at the output, a microcontroller and a digital potentiometer are powered from it. The ATMEGA 328P microcontroller generates a digital signal (the degree of motor speed) and is fed to a digital potentiometer, which converts the digital signal into a resistance. After the control voltage is formed, it is fed to the operational amplifier in which it is amplified to the values of the controller PLN 40.

The batteries must be recharged during their operation. For autonomous operation of the robotic platform and electric power management, a system has been developed that automatically supports the rated charging modes of the battery. To recharge the battery, an $\mathrm{AC} / \mathrm{DC}$ converter is used, which converts an alternating voltage of $220 \mathrm{~V}$ to a constant voltage of $24 \mathrm{~V}$ and with a maximum current of $125 \mathrm{~A}$. The robotic platform uses four $12 \mathrm{~V}$ batteries, two batteries for each engine. All batteries are connected to a single power supply system. All four batteries are charged simultaneously. The maximum battery charge current recommended by the manufacturer is 10 amps. When connecting the AC / DC converter directly to the batteries, the charging current will be equal to $125 \mathrm{amps}$, which will lead to premature failure of the battery. For this purpose, a current stabilizer is used (Fig.5). 


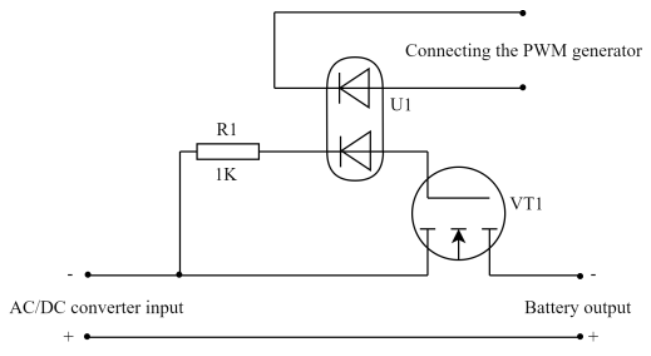

Fig. 5. Current stabilizer circuit

The use of a current stabilizer will limit the charging current of the battery, the current value is regulated by changing the duty cycle of the PWM generator, which is connected to the field-effect transistor VT1. The ICE2QR2280Z controller with a conversion frequency of $25 \mathrm{kHz}$ is used as a PWM generator.

To turn the wheels of the robotic platform, an electric drive, a stepper motor is used. For precise positioning of the turning of the wheels, a control method has been developed that can be connected to a single control system of a robotic platform. A bipolar stepper motor ST57-100 is used as an actuator for the steering of the robotic platform, which is connected through a coupling to the steering gear. To control the stepper motor, the DM556E LEADSHINE driver is used, which is powered by a battery voltage of $24 \mathrm{~V}$. 4 wires are connected to the microcontroller, VCC power supply of the microcontroller is $5 \mathrm{~V}$, PUL is used to generate the number of steps using a PWM signal, DIR is the direction of rotation of the stepper motor, ENABLE permission to enable the driver.

As a result of the research, a robotic platform control system was developed (Fig. 6).

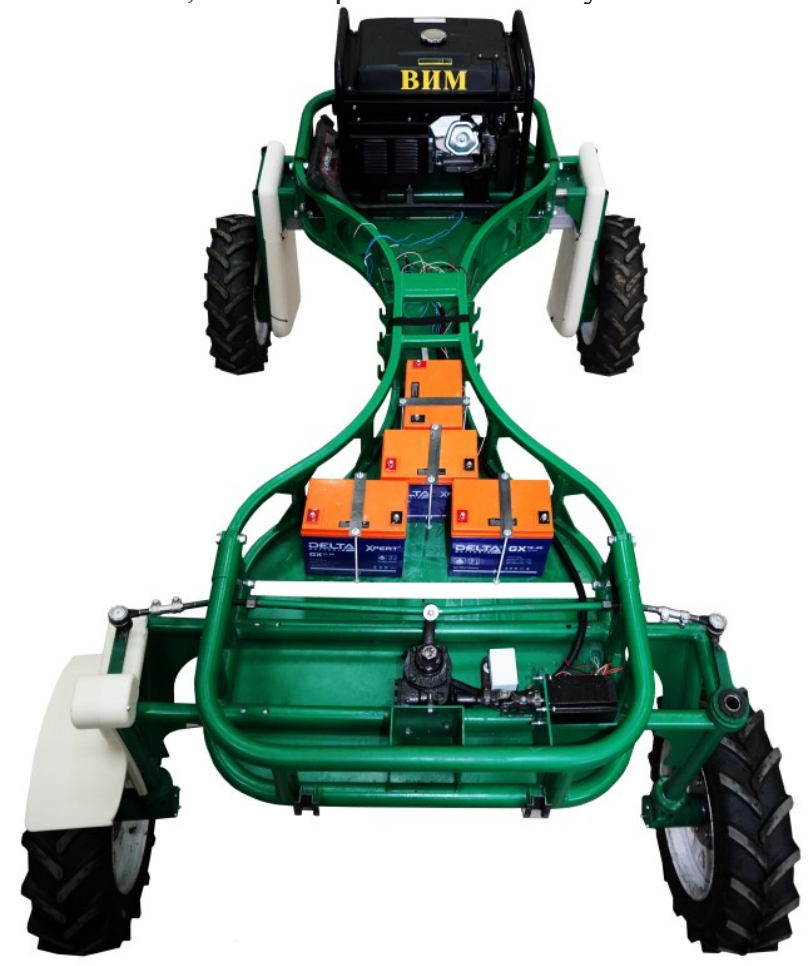

Fig. 6. Robotic platform with a developed control system 
After installing the stepper motor on the robotic platform, the positioning accuracy was calibrated, the microstep, the torque on the shaft, and the driver supply current were adjusted. A sensor is connected to the steering gear output shaft to monitor the steering angle, as well as to monitor the skip of engine steps. A CNIKESIN 400 encoder is used as a rotation angle sensor. The encoder is connected to the microcontroller via a digital port, power is supplied via a $5 \mathrm{~V}$ microcontroller circuit. When you turn the encoder, pulses are issued, which the MC reads. 1 impulse equals 0.90 rotation angle. If the stepper motor skips the steps, the encoder will fix this moment, then the microcontroller will command the driver to increase the current on the windings when the next step is applied. The current will increase until the encoder detects the rotation of the stepper motor shaft.

\section{Conclusions}

The developed control system of the robotic vehicle contains a central computer that collects information from sensors and sensors, processes it and transmits control signals to the drives of the machine movement. The movement of the robot is carried out both by a radio signal with a remote control, and in offline mode on a pre-set map of the area according to data from the GLONASS / GPS differential receiver of the satellite navigation system. A base correction station is used to provide a reliable satellite signal. Signals are transmitted from the robot to the control tablet via a WI-FI channel at a distance of up to $200 \mathrm{~m}$. It is also possible to independently control the movement of a robotic platform using a vision system.

An analysis of technological application schemes on various horticultural crops showed that a robotic platform with various attachments can be used for harvesting horticultural crops, spraying, cultivating the soil on low-growing berry fields with a row spacing of 750 $1000 \mathrm{~mm}$, in intensive-type gardens with a row spacing of $2.5-5 \mathrm{~m}$ and shrub berry fields with plantings between rows of 2.5-3.5 m (Fig.7).

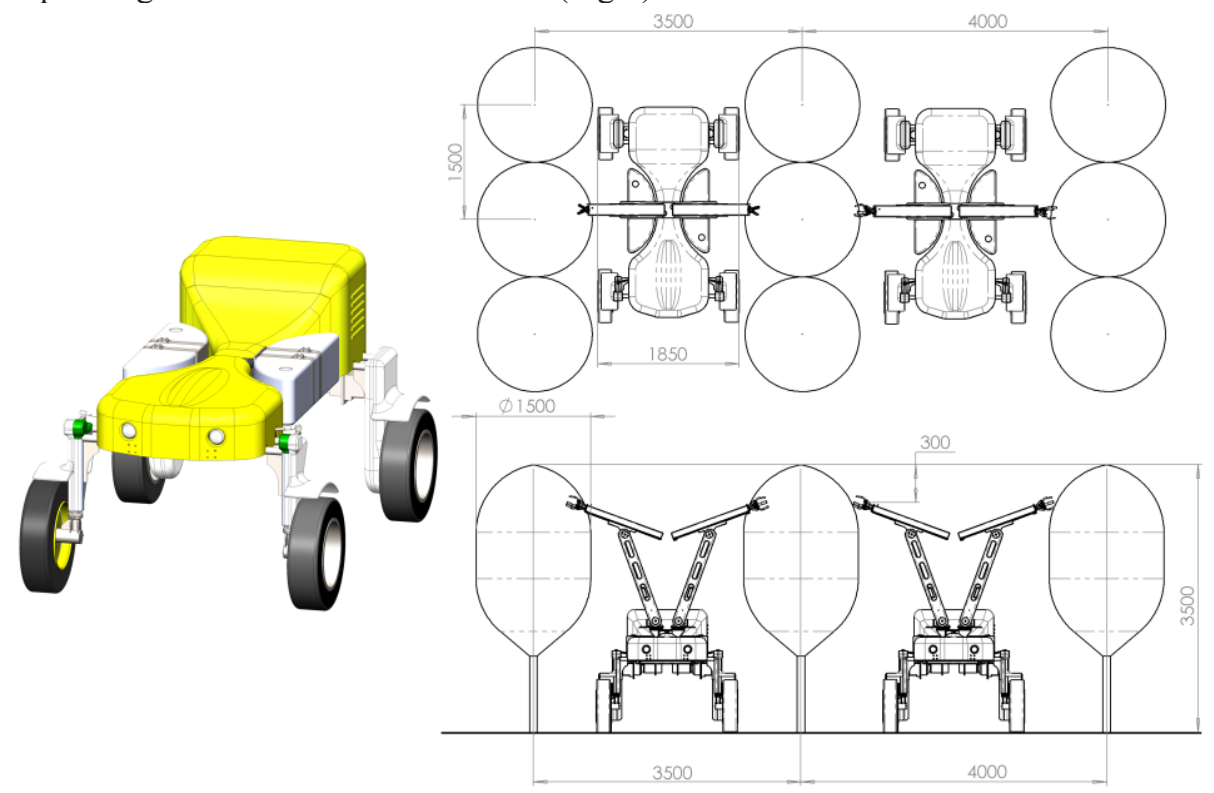

Fig. 7. Scheme the use of a robotic platform during the harvesting operation of horticulture crops

The autonomy of the robotic platform provides 10 hours of continuous operation in low light conditions in various weather conditions. 


\section{References}

1. Zhenghao Fei, Stavros G. Vougioukas, Computers and Electronics in Agriculture, 180, 105894 (2021)

2. M.E. De Kleine, M. Karkee, Trans. ASABE, 58(6), 1461 (2015)

3. D. Khort, A. Kutyrev, I. Smirnov, V. Osypenko, N. Kiktev, Communications in Computer and Information Science, Springer, Cham, 1158 (2020)

4. D. Khort, A. Kutyrev, R. Filippov, N. Kiktev, D. Komarchuk, Science and Technology (PIC S\&T), Kyiv, Ukraine, 869 (2019)

5. Rui Suo, Fangfang Gao, Zhongxian Zhou, Longsheng Fu, Zhenzhen Song, Jaspreet Dhupia, Rui Li, Yongjie Cui, Computers and Electronics in Agriculture, 182, 106052 (2021)

6. P.A. Dias, A. Tabb, H. Medeiros, Comput. Ind., 99, 17 (2018)

7. F. Gao, L. Fu, X. Zhang, Y. Majeed, R. Li, M. Karkee, Q. Zhang, Multi-class fruit-onplant detection for apple in SNAP system using Faster R-CNNComput, Electron. Agric., 105634, 176 (2020)

8. L. Fu, Y. Majeed, X. Zhang, M. Karkee, Q. Zhang, Biosyst. Eng., 197, 245 (2020)

9. H. Kang, C. Chen, Comput. Electron. Agric., 168, 105108 (2020)

10. Z. Zhang, C. Igathinathane, J. Li, H. Cen, Y. Lu, P. Flores, Comput. Electron. Agric., 175, $105606(2020)$ 